\title{
The Role of Supply Chain Management on Organized and Unorganized Grocery Retailers-A Review on Indian Perspective
}

\author{
Raghuram Naga Venkata J. ${ }^{1}$ \& Ravilochanan $\mathrm{P}^{2}$ \\ ${ }^{1}$ VIT Business School, VIT University, Vellore, India \\ ${ }^{2}$ School of Management, SRM University, Chennai, India \\ Correspondence: Raghuram Naga Venkata J., VIT Business School, VIT University, Vellore, India. E-mail: \\ jeenvrr@gmail.com
}

Received: January 25, 2014 Accepted: August 9, 2014 Online Published: October 30, 2014

doi:10.5539/ass.v10n22p1 URL: http://dx.doi.org/10.5539/ass.v10n22p1

\begin{abstract}
The retail industry in India is slowly taking a new shape and structure. The dominant unorganized retailing started losing its stand in the market and the organized sector is taking its importance in the industry. The organized retailers have changed the perceptions of the consumers and chased out the consumer from the unorganized retailers.

What the customers look for from today's retailers is ambience, price, variety, assortments and merchandise which are addressed meticulously by the organized retailers. With a change in the purchasing power, tastes and preferences of the Indian retail consumer, read availability of product with the retailer is playing a major role in the sustainability of the retailers. In this context supply chain management (SCM) plays a vital role. The mechanism which helps in decreasing the waste, decreasing the inventory, decreasing the transportation cost, finally giving, the consumer an affordable price and improving the performance of the retailer is what is called as Supply Chain Management. This article emphasis on the role of SCM in the organized and unorganized Indian retail and the roles of various factors like information flow, inventory management, sourcing, transportation, warehousing, reverse logistics, demand forecasting and supply chain execution as key drivers for an efficient supply chain management.
\end{abstract}

Keywords: grocery retailers, supply chain management, logistics

\section{Supply Chain Management}

The process of strategically managing the product procurement, movement, storage and the inventory (and the related information flows) through the organization and its marketing channels in such a way that current and future profitability are maximized through the cost effective fulfillment of orders. (Christopher, 1998, p. 4)

SCM helps to procure and supply the products and services smoothly right from the supplier to Manufacturer and from there into the hands of customers in order to fulfill their needs. This smooth flow of product from the starting point till the end point is done with mutual relationship with each other.

\subsection{Channels Used in SCM}

There are different channels which the retailers follow. To name a few;

\section{1) Limited Channel}

This is one type of channel where the retailer eliminates the intermediary, keeping a direct contact with the producers, thereby eliminating the cost of using wholesalers.

\section{2) Direct Channel}

The product is sold by the producer directly to the customers. This is what we term as the forward integration. Producers move a step forward to establish their own outlet to sell their product to the consumers directly. This facilitates cost reduction as retailer is eliminated.

By using both the channels mentioned above, modern SCM practices enabled the producers and retailers to minimize the distribution. This in turn reflects on the price and customers stand to gain by virtue of lower prices. This creates a win-win situation for all the players in a channel. These advantages are realized more by organized 
retailers than unorganized.

Today's customers' expectations are increasing day by day and probably nothing can substitute the availability of the stock at the time of customer's requirement. This satisfaction will be more than the services provided or the value added promotions provided.

\subsection{Components of Retail Sectors}

The retail sector across the globe is experiencing enormous growth and complexity. On the other hand this trend is upgrading the life-style of every households and individuals thus contributing to the rise in globalization of trade. The sectors like agriculture and other industries are maintaining the forward and backward linkages with the retail sector, so as to build relationship and stimulate the demand for their products through mass marketing. Moreover, it creates considerable direct and indirect employment in the economy. Also, the consumers have benefited in terms of wide range of products available in a market. (etd.uasd.edu)

The retail sector consists of organized and unorganized segments. The organized retailers include hypermarkets, super market, discount stores, mega markets and many more formats which are supported by big private and corporate giants. These formats of organized retailing involve huge investment and offer large assortments of goods.

The unorganized Indian retailers like Kirana stores or the local mom and pop stores, convenience stores, etc. were all low-cost retail shops and mostly run by an individual or a family. These stores used to have lesser assortments and their business depends on the relationship with the consumers. The business volumes are less and they rarely followed any systemized procurement or storing procedures. But today retailers should provide what is wanted by consumers and not what they can sell. Hence the system of procurement, storing, suppliers' selection and other activities which help the retailer keeping stock of products ready for the consumer, have drastically changed. Thus there is a need for new procurement policies, new storing policies, new pricing policies, new packaging policies paving the way for an efficient system. This is called Supply Chain Management and Logistics. SCM Practice therefore has three constituents-Supply chain Planning, Sourcing and procurement and Supply chain execution. An efficient SCM practice will enhance all these constituents and thus will enable the retailer to deliver the right product to right consumer, at right time and at right price.

\subsection{Organized and Unorganized Retailers-Indian Scenario}

The value of transactions in the organized and the unorganized retail in this country was around $\$ 328$ billion in 2010. This is expected to reach $\$ 450$ billion by 2015 . On the other hand the organized retail was around $\$ 16.4$ billion ( 5 per cent share) in 2010, which was projected to reach $\$ 49.2$ billion (11 per cent share of expected value of 2015) by 2015. This clearly indicates that there will be a tripling effect in the size and scale of organized retail by 2015. While organized retail will grow at this fast pace, it is important to note that the unorganized retail sectors will bring about the rest of the value. In fact this segment will reach $\$ 73.8$ billion by 2015. (Techno park Advisor, 2010).

\subsection{Justification for Selecting Retail Grocery Markets}

With such a prospectus for retail business the role of Supply Chain Management in retail segments needs an in depth study. But the retail sector deals with huge assortments of goods and for the purpose of study only grocery items in retail business are included.

\section{Indian Grocery Retail Market}

The traditional kirana stores constitute over 50 per cent of the Indian retail market and have an annual turnover of US $\$ 80$ billion. (Goswami \& Mishra, 2009), about 6.5 million grocery stores are estimated to have their presence in this country in various shapes, structures and sizes. But most of them are fragmented. In the current developments taking place in the retail industry the organized retailing is slowly gaining its presence in the urban market. As of now the organized retailing is very low and is only $2-4 \%$ in the market. The changing pattern of the consumer's purchases, needs and demands are impacting the organized retailer in urban areas.

CII-McKinsey \& Company, 2005 have stated that Grocery sector can be classified into three components: (1) The packaged foods, soaps toiletries household items etc. which all come under the branded grocery products (2) Grains and cereals which come under the dry unprocessed unbranded grocery and (3) Fresh Vegetables, fruits, dairy products, meat etc. are categorized under Fresh grocery. Generally the Unbranded products nearly account for about $60 \%$ of all packaged food sales. About $40 \%$ of the food business includes $18 \%$ of milk, $13 \%$ fruits and vegetables and $9 \%$ of meat under Fresh groceries categories in India.

The grocery sector in India till 1990 was contained by Haats, Mandis, Bania shops and after that it includes Apna 
Bazaar, Kendriya Bhandaar and from 2003 onwards, the era of organized retailers like Subhiksha, More, Spencer's and many more started.

The old practice of retailers stocking daily items in very small shopping space with no parking lot has given place to well stocked items, very clean and neat environment, and fresh stock, huge variety of stock, loyalty programs and above all low price. As the disposable income has increased and consumers have become very much brand conscious, they are always looking for big assortments and wide variety at affordable prices. This combination of wishes and tastes of the consumer are changing the pattern and the business model of today's retailers.

\subsection{Demographic Details of Indian Retail Grocery Sector}

India in the current situation is becoming a focal point for all the global trade towards the strategic off shoring and becoming an appealing market.

Out of $6,40,000$ villages in India, about 87 per cent of villages have population of more than 2000 people. Despite a rough estimation of about 3.6 million rural retail outlets, the distribution and marketing in these villages are very low and all this is because of uneconomical logistics (Deveshwar, 2005). Therefore most of the multi nationals are not showing interest in entering the rural markets.

In 2013 the multinational food companies with foreign direct investment (FDI) was worth of \$2.14 billion and continue to increase significantly. As of now the Indian retail market is estimated at $\$ 490$ billion and is estimated to grow at a pace of 6 per cent to reach $\$ 865$ billion by 2020 .

A panel from Seventh Food and Grocery Forum pointed out that the grocery and food retail in this country will be about 69 percent of India's total retail market. (Seventh Food \& Grocery Forum report, 2009).

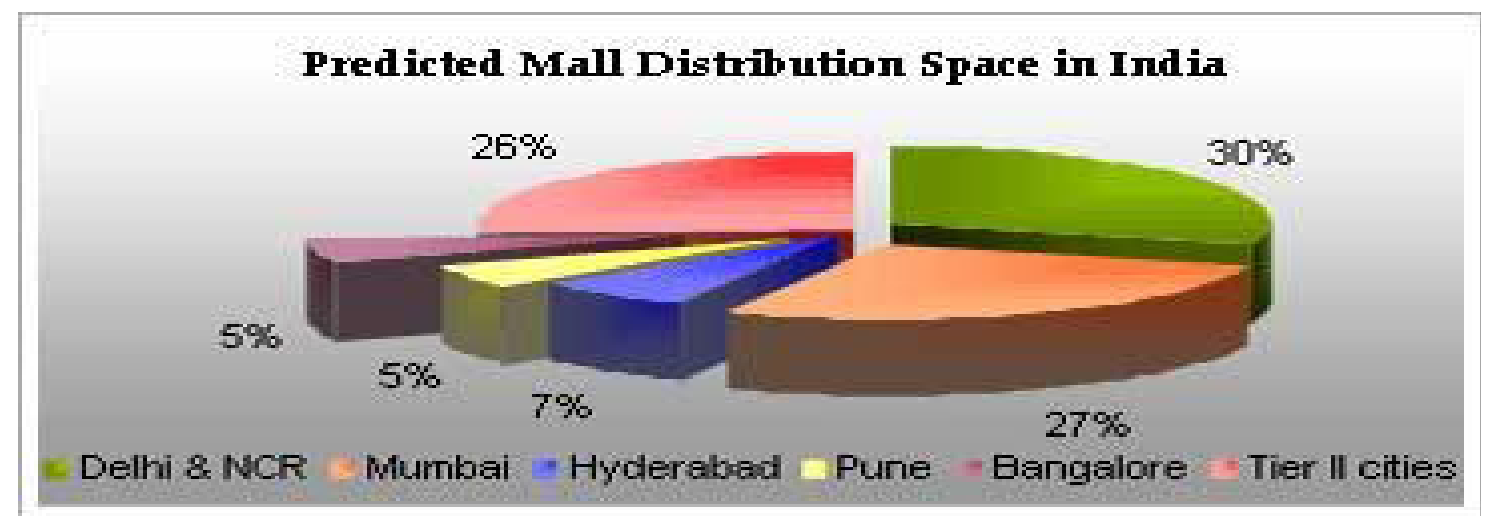

Figure 1. Predicted Mall Distribution Space in India

Source: Technopak Analysis, CSO and other sources

\subsection{Retail Trends in Indian Grocery Market}

There is a huge growth of mass discounters like Wal-Mart, Big Bazar and many more organized retailers. To fight with these big giants the small traditional retailers and the traditional departmental stores also started restructuring and repositioning themselves. On the other hand with the increase of huge competition and modernization, private labels started dominating and competing with the branded products. In addition to these the internet shopping has given a new shape to the retailing and the new light to the SCM practices.

The product should be available and always should reach the customer on right time. For this to happen there should be some process which makes the product move from one phase to the other in right time through right channel with less cost involved. When the system or the process through which the movement of the product is done properly with the reduction of wastages, right price can be set.

\subsection{Percentage of Cost of Distribution}

In the year 2013 the grocery retailers have recorded a growth with an increase in the current value by $11 \%$ to Rs.16, 172 billion. The unorganized or the traditional retailers during this year accounted for $98 \%$ of total value of sales, thus dominating the industry.

Grocery retailers in India continues to shift towards modern grocery retailers channels, with hypermarkets and 
supermarkets witnessing current value growth of $29 \%$ and $15 \%$ respectively during the year. (Euromonitor International, 2014)

In the current grocery retail scenario, one important point is very much about supply chain management. Currently about $75 \%$ of a typical product's cost is tied up in the supply chain. (Mishra \& Hall).

\subsection{Impact of Pricing on Indian Consumer}

The price factor in the Indian Market plays an important role in the performance of the retailer. Indian consumers precisely give emphasis on pricing of the product; hence the retailer must definitely offer the product at a very economical price. However today with the changing marketing strategies and the retail trends the companies started giving importance to various techniques of reducing the overall cost so as to reduce the prices and serve the consumers, without decreasing the importance on large variety and customization. Thus the competitive position in the market and the acceptance of the product by the consumers and the quality of the product is all defined by one factor called Price. (Dolan \& Simon, 1996; Gabor \& Granger, 1966; Sivakumar, 2000b, p. 294).

The retailer's differentiation cause an increase in the price levels at multiple points, though the price consciousness by the consumer is increasing. Of course just based on pricing we cannot ascertain all facets of competition because toady every retailer is willing to "give up", but in some contexts price is always an important measure of both marketing and financial strength. (Personal communication \& Messura, 2006). All this can be possible only through proper Supply Chain Management.

\section{Literature Review}

Unavailability of cheap funds for investing in the back end infrastructure for fresh produce, grading, packaging and storing in cold storage is the primary reason for no developments in the retail segment. Chetan Ahya (2006)

There is a growth in the retail industry and lot of change is happening in the industry. The growth of the changing habits of the consumers coupled with the growing market size in this country will double to $\$ 150$ billion by 2025 . Increasing innovative formats, changing patterns, changing demographics and habits make the fuel for the growth of the organized food retail industry. Though the expectations are high, the real term growth is crippled by the sub-optimal supply chain management caused by low investments. KPMG (2010)

A research on how the consumers stated moving form unorganized to the organized retailers while shopping the groceries was done and the author found that the major reasons are because of quality, timely available of the stock and good SCM practices Goswami Paromita (2009).

The replenishment based model will focuses on supply chain improvement rather than the forecast based model, which enables the companies to increase sales by $20-30$ percent in six months and within two years the company can increase the sales by $5 \%$ in the gross margin. Strategic sourcing can reduce expenses by 10 to 30 percent and today it is the era of collaborative models of multiple suppliers. Rajesh Sinha.

Today the retail industry is facing huge problem regarding the wastage and it is because of the inefficient supply chain system. Almost about $20 \%$ of the food produce worth of Rs.10,000 Crore is getting wasted. Unless and until the retailers develop an efficient SCM practices they cannot have access to affordable superior quality food produce at an affordable prices.

The factors like Demand forecasting, data integration, financial flow management, supply-demand matching, collaborative forecasting, information sharing and synchronization of the movement of goods through efficient transport scheduling have to find their way into the food supply chain. The supply chain cost is about $12-50 \%$ across product categories and which now the focuses of the retailers to reduce this cost and thus make the product available to the consumer at a very economical price. In fact along with all this there is a huge development in the supply chain innovations, dominance of private labels, infrastructure and the policy amendments, which always creates lot of challenges for the retailers. Viswanadham (2010).

Chew et al. (2009) identifies the supplier Retailer relationship in context to the small retailers and look on the issues related to small and medium retailers about their efficiency and adoption of the new technologies.

Measure Twice, Cut Once-Planning, attention to details, and tested programs build excellence in retail operations A. T. Kearny (2010).

One of the researchers has done a study with a four stage framework consisting of:

1) Driving store value through voice of the customer, channel strategy and store business planning;

2) Delivering core store value through supply chain interfaces and store operations;

3) Enhancing store value through store life-cycle management, operating expense control and store technology 
and finally;

4) Using the learning store for roll out.

This survey was conducted jointly by FICCI and E\&Y. It highlights the key drivers of retail, drivers of change in supply chain, the paradigm shift from the traditional supply chain towards adoptive and real-time supply network with bi-directional information flow, retail supply chain challenges and mitigation strategies. Pinakiranjan Mishra, Ernst, \& Young (2007).

Today there is huge competition the local kirana stores are facing and it is becoming difficult for the companies to understand the customers. Apart from this the SCM practices based on Inventory management, demand forecasting, replenishment, procurement and transportation, storage and many more are concentrated and discussed. This article emphasis on the issues and challenges the retailers are facing in implementing the SCM practices. Ketan Dewan, Footfalls, June (2010). One of the research focuses on the RFID implementations and its use on proper stocking of the goods on the shelves. The out of stock situations are very crucial in the proper flow of the Supply chain Practices. Ravi Mathur and Gopal Valecha, Footfalls, (2010). The inefficient inventory management is a leading cause for an inefficient supply chain management. Huge cost is invested in the improper inventory and thus huge capital is getting strained in the balance sheets. Raghav Gupta, Rohit Bhatiani and Pranay Gupta, (2010). The author highlights on the emergence of collaborative models in retailing and defines the focus on the retail back-end which is supply chain Management. Anil Rajpal \& Pragya Singh (2009).

\section{Research Gap}

Most of the literature emphasis on the importance of the Supply chain management and various tools of SCM having impact on the business of the retailer. But the gap identified is to find the significance of various variables on the Supply chain Management process.

\subsection{Research Objectives}

1) To identify the variables influencing the outcome of supply chain practices of retail grocery segment.

2) To elicit the relative benefits or advantages gained by the retailers with an efficient Supply Chain Practices.

\subsection{Research Questions}

1) Do the organized and the unorganized retailers follow different Supply chain practices?

2) What are various factors which play significant roles on the Supply chain Management practices?

3) What relative benefits or advantages are gained by the retailers with the Supply Chain Practices?

\section{Methodology}

Aim of this paper is to identify the variables influencing the Supply chain Practices of the Indian retailers and the changing trends of the retail industry with reference to the grocery store.

In the competitive scenario prevailing in the retail industry today in India, each retailer has to acquire strength in his SCM practices. This calls for a close day to day monitoring of the SCM constituents, so that the retailers would be able to achieve success over their rivals. Unorganized retailers need to strengthen their competitive advantage by revamping their SCM practices by studying the SCM practices of successful organized retailers. This alone can help them to sustain in the trade and grow. With a revamped SCM practices these retailers would be able to supply right product to the right customer at right time and at right price. So the focus should be on the following constituents of the SCM practices: procurement, inward and outward logistics, inventory, pricing and managing shelf life of products. Hence this article focuses on supply chain planning, sourcing and procurement and execution practices adopted by the Indian retailer and how they need to function for a better performance.

\subsection{Sources of Data}

The sources of information required for this paper was collected from journals, editorials, professional communities and internet resources and from various Supply chain Management magazines and text Books reviews. All the sources which are considered to include works in Supply chain Management and on Retailing were considered for data collection

\subsection{Challenges Faced by Indian Retailer in Following the SCM Practices}

Though there are a lot of developments happening in the retail industry across the globe, in India there are many challenges the retailers need to face in implementing the SCM practices. 


\subsection{Complex Structure}

Retail supply chains in India include a large number of intermediaries, resellers and distributors facilitating collaboration between retailers on the one end and farmers or consumer goods manufacturers on the other. Fragmentation issues make it difficult for retailers and their suppliers to effectively collaborate on forecasting, replenishment and inventory management. (Supply Chain Brain, 2013)

\subsection{Taxes}

The tax system in India has a major impact on Supply chains. The complex system of state, national, city taxes on every product will add extra amount on the pricing and thus creates a hurdle in building an efficient supply chain system. In fact to reduce this complexity and increase the interstate trade, the government of India has also introduced a system called Goods and Services Taxes (GST), which aims at integration of taxes. However this system will definitely help the development of transport and warehousing hubs across the country and may lead to a better SCM practices.

\subsection{Infrastructure Building}

As of now the Indian market which is dominated by the unorganized retailer, who rarely have given importance to the SCM practices or the logistics and other infrastructure development. But today to survive in this current competitive market, the retailers need to concentrate on the infrastructure availability which can be the backend support. Before a retailer starts a shop he has to evaluate the logistic services available and other value added service providers available. Currently the third party logistics providers and service providers are very less. Their increased presence in the country will support Supply chain process maturity, regional scope and capabilities.

\subsection{Training the Personnel}

Most of the retailers are unorganized and never had any system of logistics or SCM practices. Though they practiced some raw methods, most of their processes ware done only by an individual and very few partners in the chain. But now as the system is increasing and developing, the personnel have to be trained on the system prevailing and the technology used for the same. So technological up gradation is necessary. The retailers also need to invest on the training of other partners.

\subsection{Lack of Collaborative Process}

It sometimes seems to be difficult for the Indian Retail firms and their supply chain partners to collaborate on forecasting, replenishment and inventory management processes. Because of this lack of collaboration, longer lead times and inefficient end-to end supply chain takes place. (Viktoria, 2013).

Though retail in India is making progress and is expected to grow more than $\$ 879$ billion by 2018 , the country loses $\$ 65$ billion every year due to inefficient supply chain systems, says a study report. As per the report published by CII, India is ranked 47th rank on logistics when compared with Japan, US, Germany. Currently, the retail industry in India is a $\$ 410$ billion market and is expected to grow to more than $\$ 879$ billion by 2018 . Food and groceries account for $70 \%$ of the retailed items followed by textile and apparel at $7 \%$. However, $95 \%$ of the retail sector is unorganized and fragmented.

\subsection{Other Challenges}

At the company level, retail in India is facing challenges like product proliferation, high-level of intermediaries, fragmented and large number of retail outlets, suboptimal supply chains and lack of supply chain visibility. (Moneylife Beta, 2014)

To bring a balance between the supply chain practices adopted so far and emerging trends and futuristic technologies, one of the reports suggests adoption of an "intelligent supply chain". It speaks of a paradigm shift from traditional supply chains towards adaptive and real-time supply networks. "To achieve profitable growth over the next few years, supply chains need to be realigned into efficient, agile and adaptable networks," says the report. This, in turn would help manage costs, ensure product availability and be highly responsive. (Aggarwal, 2007)

There is a need for informational and technological intervention to tackle the current bottlenecks by using supply chain technologies like Radio Frequency Identification, barcode scanners, point of sales terminals, hand held devices and software packages. It reveals that 85 per cent companies use IT to capture and analyze real-time information for effective decision making.

The growth momentum is very strong in the Indian retail sector. Both domestic and foreign investors are expected to continue their expansion in this sector in 2013 and beyond. However, they need to be aware that this 
market is very diverse and complex, and currently the prevailing supply chain represents a major hurdle to establishing effective operations and achieving profitability. Retailers should think that an efficient supply chain will be poised to achieve competitive advantage in this fast-growing market.

\subsection{SWOT Analysis of SCM Practices}

Foreign Direct Investment (FDI) in retail has been a contentious issue in India for years. International supermarket chains like Tesco, Wal-Mart and Metro have been pushing for restrictions to be lifted to allow them greater access to one of the world's fastest growing retail markets. With the Globalization and liberalization there is a huge development of economy with the increase of lot of multinational products and thus the development of Supply chain practices and logistics took place which eventually lead to the growth in food industry and processing industry.

\subsection{Strengths of SCM Practices in Indian Retailing}

India has the highest number of retail outlets in the world at over 13 million retail outlets, and the average size of one store is $50-100$ square feet. It also has the highest number of outlets $(11,903)$ per million inhabitants. The per capita retail space in India is among the lowest in the world, though the per capita retail store is the highest. Majority of these stores are located in rural areas.

As majority of the unorganized grocery retail stores are concentrated in rural areas, by adopting improved SCM practices, they can exploit the rural market at relatively lesser cost and better integration practices.

An organized retail segment has established a huge networking with many suppliers and manufacturers and record efficient performance. By strengthening the relationship with Agro business value chain and sources, this segment has enormous scope for achieving better prospectus.

The grocery retailers can also achieve scale economy thereby improving their competence in the SCM practices. In this regard over hauling the current trade network in the grocery segment can grow at a faster rate.

An efficient SCM practices will give lot of advantages on the costing of the product over the rivals. It becomes strength for the retailer in creating distinctive competence in distribution systems at the same time an automated and efficient distribution of goods into its stores, from manufacturers to its fleet of delivery trucks that made daily deliveries to surrounding stores.

\subsection{Weakness of SCM Practices in the Indian Retailer}

Majority of the Indian Retailers are all very small and handled by single owner with less investments they mostly cannot invest huge money on technology developments or any other necessaries for the improvement and the implementation of better SCM practices.

As most of the Indian Retailers all having some crude structure of relationships with all the suppliers which they maintain may never lead them for the emergency of the latest technologies and other infrastructure for the SCM practices. But these with the increase of the organized retailers in this country are making the unorganized retailers face difficult situations and thus are facing big challenges.

Retailing is subjected to a plethora of laws and regulations. There is no uniform tax system in this country with multiple layers of taxes. Retail sales in this country accounts for 44 percent of GDP. Modern and the organized accounts for just about 1.6 per cent of total retail sales.

Another important point is that the data related to the sales at Point of Sales (POS), Sales Volume, inventories, proper warehousing, warranties, compliance issues, improper planning of the end-of life goods, suppliers selections, procurement policies, financial issues, customization of the distribution process, quality systems, reverse logistics, proper spend analysis should all be properly maintained and should be shared with the other partners of Supply Chain members. But in this country the major weakness is improper flow of information and lack of relationship among channels partners. It is known that better that the collaborative planning will give better results than the individual planning for an efficient Supply chain management.

\subsection{Opportunities before the Indian Retailers}

The Indian government recent policy decision to allow $51 \%$ of Foreign Direct Investments (FDI) in multi brand and $100 \%$ in single brand retail created a huge opportunity for many retailers to expand their markets. The FDI openings increased the opportunity in establishing the Cash and carry formats, Single Brand retails space. The giants like Metro, Wal Mart and Tesco have already entered in this country doing the business efficiently and that is all possible only with a meticulously planned SCM practice. Of course the market being dominated by $95 \%$ of unorganized retail sector is also taking care in protecting them. The government policies are creating a mandate 
for investing $\$ 100 \mathrm{Mn}$ with half of it should be invested on Infrastructure, storage, Packaging, Transporting. Further, foreign retailers will have to source a minimum $30 \%$ from the Indian small and micro industry. (Cedar)

The government policies will impact a wide cross section of the Indian population. Every consumer can save $5-10 \%$ on their regular spend and at the same time get a wide variety of assortment. Every farmer will get almost $10-30 \%$ higher remuneration for their products as a back end infrastructure investment will eliminate the middlemen.

The blend of investments and starting new retail stores can provide a way to increase the real estate and create 3-4 Mn new jobs and 4-6 Mn jobs in Logistics, Contract labor security etc.

Even though the organized retail segment has a minuscule share in the total industry, it has enormous potential considering the increasing urbanization, raising standard of living, the efficient supply-chain, the read available retail space, and modern technology, which help in reducing consumer prices to a great extent. The 700 million Indians residing in rural India are an opportunity that retail and consumer (R\&C) companies cannot ignore.

\subsection{Threats Faced by the Retailers}

Today the retailers are facing a tough time with the imitation brands. These brands are very close to the original brand and are difficult for the consumers to distinguish. (IASMS, BANGALORE, INDIA). Proliferation of duplicates in the market is posing a major threat for the grocery traders. Such duplicate products are also sourced internationally. Therefore the grocery traders become the victims of such an environment prevailing in Indian Market.

The long standing retailing in this country has seen a huge market with enormous customer's base is now facing a threat with the boom of the organized retailers. The retailers have experienced the consumers' relationships and decent business with them. The customers also had good time with the known retailers and the credit facility they got from the unorganized retailers. But now the biggest threat the unorganized retailers are facing is the change in the retail industry. The entry of the organized retailers is creating a huge impact on the consumers and thus making the consumers divert from unorganized to organized retailers. This is because of the stock organized retailers maintain the quality of the products and the technology used in serving the customers. The unorganized retailers are unable to cope up with the latest technology and thus design an efficient Supply chain practice. This is a major threat for the survival of the unorganized retailers in competition with the organized retailers. Apart from this most of the unorganized retailers may not be that much capable in implementing the latest technology as till date they never used or rather they never had the need for Technology. Thus SCM Practice requires a proper procurement cycle done at the suppliers and then the Manufacturing cycle at the manufacturer and the Replenishment Cycle at the Distributor and finally the customer order cycle at the retailers, but current system go in a very unorganized way and thus for an this may be a threat in implementing.

\subsection{Need for an Effective SCM Practices}

Today's retailers to sustain in this competitive world need to have an efficient and effective Supply chain management so as to purchase, operate and distribute the goods on time to various store and have a good integration.

Retailers need to develop and formulate a highly structured and advanced Supply chain Process, so as to enhance the competitive advantage.

\subsection{SCM Models of a Successful Retailer--Wal-Mart}

Wal-Mart has been able to assume market leadership position primarily due to its efficient integration of suppliers, manufacturing, warehousing, and distribution to stores. Technology plays a key role in Wal-Mart's supply chain, serving as the foundation of their supply chain. Wal-Mart has the largest information technology infrastructure of any private company in the world. Its state-of-the-art technology and network design allow Wal-Mart to accurately forecast demand, track and predict inventory levels, create highly efficient transportation routes, and manage customer relationships and service response logistics. Thus it is proved that the above strategies followed by Wal-Mart has given that company a huge success as a discount store, in store variety and dominant force in a competitive global market.

In the current global scenario with uncertain economic conditions, retailers need to develop more agile/responsive supply chain management (SCM) strategies. Thus retailers need to put greater emphasis on the maintenance of a proper balance between the cost and the service. (Wesley et al., 2011).

In a country like India retailing can never be as a one size fit for all the businesses and thus the literature suggests that the SCM strategies used by retailers depend greatly on the nature of each retailer's model. 
Rajeev Kumar commenting on the SCM practices followed by some Indian retailers observed that every retailer needs to share information with their suppliers relating to customer buying behaviors consistently. Sharing of information creates a foundation for mutual trust and long terms partnership thus satisfying the customers 'needs at low cost. This kind of orientation and strategy will lead to a smooth supply chain process. (Kumar, 2012)

Thus with the above issues being considered in context to the Indian environment, the model proposed for a better supply chain Process can be designed with basic three factors for the Supply chain Management. Initially any SCM practice should have some variables which always lead to a better supply chain planning. The variables like Demand forecasting, material requirement planning and many more. The second factor Sourcing \& Procurement with suppliers selections, spend analysis, procurement variables makes an important roles in the SCM practices. Along with these factors the third factor on Supply chain execution is very important in proper functioning of the supply chain management.

\subsection{Conceptual Model}

Retailing is entering into a new era and new markets where the consumers have changed with lot of expectations and demand of all store experience. Thus the availability of stock and the merchandise is very important for retaining and the acquiring new customers, which makes the retailers to follow different SCM models. The Review of literature has given an insight into many models which have discussed on various factors which play a major role on Supply chain Planning, Procurement and Execution.

An efficient and effective supply chain management differs by the format of the retailers and it is dependent on the retailer's business strategies. Different factors which were identified make the product to sell in an innovative way and thus illustrate the effectiveness of the SCM practice support for a better performance of the retailer.

In a model defined by Johanna Småros, Juha-Matti Lehtonen, Patrik Appelqvist, Jan Holmström emphasis on the vendor managed inventory, replenishments, distributors planning, non VMIs was done. They have looked on the impact of increasing demand visibility in production and inventory control efficiency. Hokey Mina, Gengui Zhou (2002) concentrated on horizontal and vertical structure of retail SCM with focus on Tier 1, tier 2 and tier 3 supplier and on the other side the customers. Adrian E. Coronado Mondragon, Andrew C. Lyons (2004) focuses on Manufacturers, warehousing, retailer and finally the consumer.

Technopak (2012) has come out with a model which focuses on stock out, inventory level, transportation cost, replenishment cost, supply \& demand planning, inventory optimization, retail merchandise, procurement, quality in formulating the SCM practice. The retail value chain works on how the integration happens and how the distributors, intermediaries and retailers play a major role in the SCM implementation. In one of the studies done by Cybage company has come out with a model emphasizing on Supply chain planning, procurement and then execution of SCM practice in manufacturing sector which looks on a value delivery of the product to the customer.

Thus taking all these models into consideration and finally identifying the factors which would make an impact in the efficient and effective SCM practice for a retailer were used to define this model. This model was framed based on how a retailer will do the supply chain planning and then go with the sourcing and procurement procedure and finally how the implementation of the SCM practice leads to the better performance of the retailer. The factors identified were tested with the factor analysis (Principal Component Analysis). The factors were tested with loading and finally some of the factors were set by the loadings. The items which had higher factor loading were considered important and were eligible for assign name or label to factor that will reflect the variables loading on that factor. (Hair et al., 2009)

For Supply chain planning a total of 41 items were reduced to 5 factors namely Demand forecasting, Vendor Managed Inventory, Material requirement planning, Logistics Planning and Inventory planning. The total forty questions reduced into five main factors explaining 39.5 percent of total variance. The items loading under these five factors were loaded between $0.78-0.43$

For Sourcing and Procurement a total of 18 items were reduced into 4 factors. The total eighteen questions are reduced into four factors viz., for self-supplier relationship, spend analysis, and contract management and supplier integration. The total eighteen questions reduced into four main factors explaining 45.7 percent of variance. The items loading under these factors range between 0.63-0.43

For Supply chain execution a total of twenty three items were taken into factor analysis and reduced into five factors viz., for reverse logistics, radio frequency identification, warehousing, and inventory management linked to execution and transportation. The total twenty three questions reduced into five factors explaining 40.2 percent of variance. The items loading under these factors range between .071-0.36. 


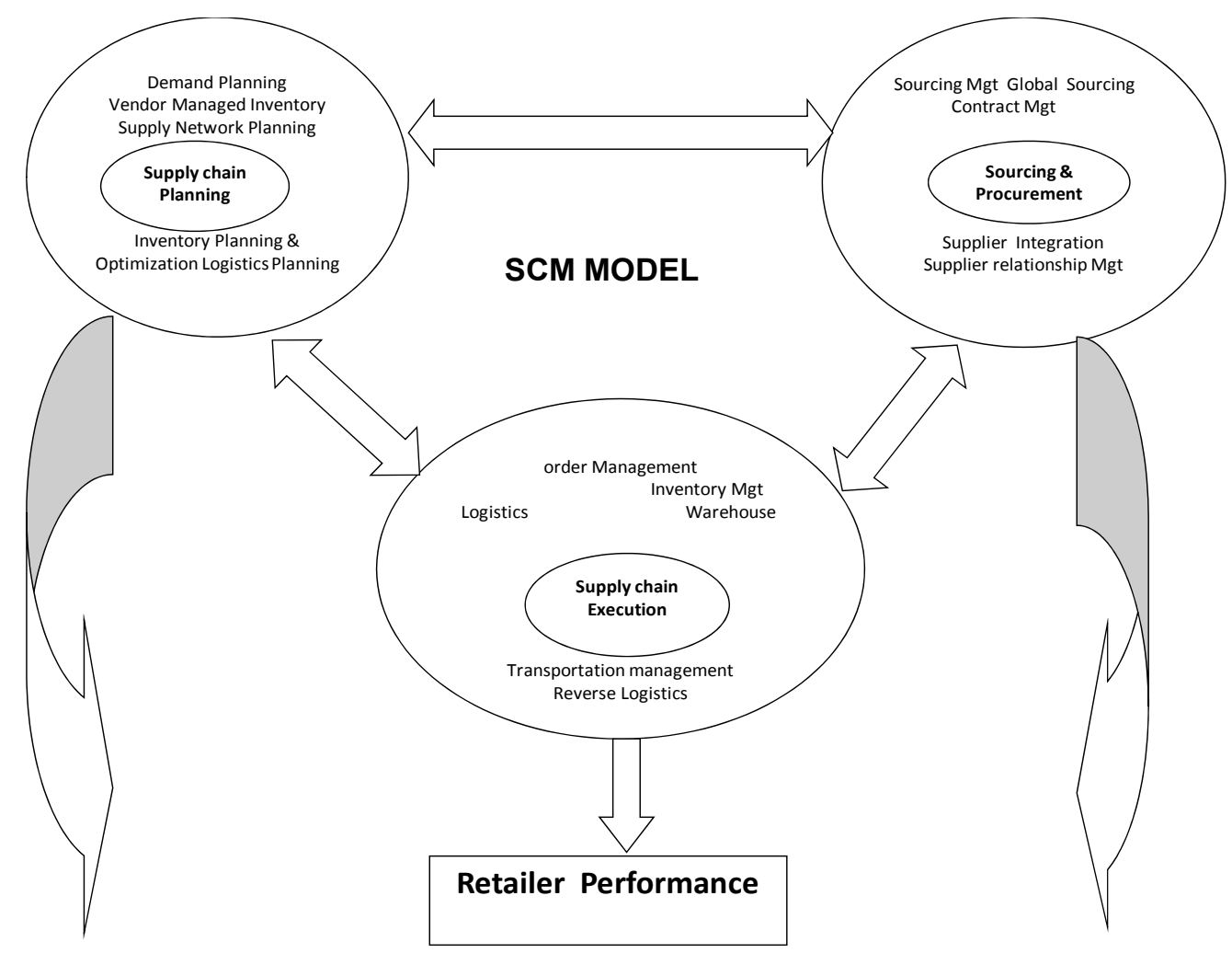

Figure 1.

\subsection{Variables of SCM and Their Roles}

The role of SCM is very crucial for the Indian consumers Demands at affordable prices and variety of product mix. It is the supply chain that ensures to the customer in all the various offerings that a company decides for its customers, be it cost, service, or the quickness in responding to ever changing tastes of the customer.

Customers and consumers today want products at low price and also the fresh product, for which the traditional methods of stocking for a long time and then selling to customer at high price will not work out in the current situation. In such situations the retailers are dependent on the "Just-in-time" concepts and also providing a fresh product at a very low price. This is how the evolution of the low and affordable priced and fresh product delivery has taken an important role in the SCM practice.

These situations became hard for the unorganized retailers to stock and create a low priced product and drive the consumers towards them and on the other side with the entry of large companies with huge investments are creating many strategies to fight the competition. However the unorganized sector which has created generic impressions in the minds of consumers as credit facility and long attachment is also able to maintain their business comfortably with their SCM practices and business model.

\subsection{Every Day Low Pricing (EDLP)}

The organized giants started coming out with the concepts of Every Day Low Price policies, store development, retailer-supplier relationships and general aspects of the reorganization, which play a key role in the efficient functioning of many retailers. (www.ingentaconnect.com) Studies highlighted on how retailers are trying to escalate their profit margins by strategically setting initial prices before the markdowns and at the same time decreasing the supply chain costs. Designing more efficient operations as well as lowering inventory levels aid in cutting overall supply chain costs. It is also evident that in spite of efficient SCM practices the profitability of the retailers may not increase as the consumers are getting the products at the lower prices and thus consumers are real beneficiaries from more efficient SCM practices.

The major category dominating the organized and the unorganized retailer will be by the FMCG goods and SCM activities linked with FMCG goods will play a major role on the performance of the retailers. Some of the key issues related to the retail industry are order fulfillment and replenishment which discusses on primary sales, stock level at each link in the chain. This information is linked to the supply chain elements like inventory 
visibility, retail level data and bottom up information aggregation. The SCM practices also emphasis on the stock levels, aging sales vs. production and stock, possibility of sales promotion. More than this the performance of the retailer also depends on how the retailer forecasts sales, current trends, inventory levels etc. SCM practices also looks on the replenishment activities and the freight management, packaging, warehousing etc.

\subsection{Stock Keeping Units}

The unorganized retailer are very much dispersed, not much buying power for the retailers and even the customers, but today with the increase of larger retailers every retailer is concentrating on number of SKU's and with high number of variety, sizes, offers. Thus rationalization of SKU's is required to customize the cost.

According to Economic Times Intelligence Group (ETIG, 2002) how to get the product at the right time, in the right quantity, assortment and best cost is the challenge for retail logistic. Most of the companies state that they undergo the process of Cost cutting, but heading the list was control of supply chain cost.

\section{Retail Logistics}

David Gilbert 2003 quotes that Retail logistics is the organized process of managing the flow of merchandise from the source of supply to the consumer- from the producer, wholesaler through the warehouse, transport to retail units until the merchandises sold and delivered to consumers. The major functions of this system is to move the goods, holding the goods at the stock keeping units and holding the stock in sufficient quantities to meet the demand from the end customers.

\subsection{Supplier Relationship}

New ventures and alliances and negotiations with vendors is increasing and the concept of third party units is also increasing rapidly. Supplier Relationship is other important issue which an efficient SCM practice will address. Most of the retailers today are very much concerned by the suppliers and vendors relationship with each other. To quote an example-Subhiksha's problem slowly lead to the closure of the store. An unhealthy relationship will create lot of problems in running the business. The company Subhisksha faced problems with the retailer's payment track records and later the vendors stopped supplying the products to retailers as there was a gap in the payment scenario.

The channel relationships will create a cordial relationship between the members in the chain and thus will have a smooth flow of the product from one point to another and finally the consumer.

The customer's satisfaction can be assured when the feedback from the consumers and the feedback from various points in the channel members reach the manufacturer than the grievances and the actions taken to solve them will be reaching at the right time and to the right point in the chain.

\subsection{Transportation}

Another major issue the organized retailers or the unorganized retailer face is the internal logistics problems; this is in fact a major challenge for the retailers. Today it's an era where the consumer is becoming more time conscious and more demanding, the need for just-in-time (JIT) services are increasing. Most of the large retail chains are following the western style of outsourcing the logistics' to a third party, so as to better manage the complex supply chain network and thus focus on their core business.

Some retailer as discussed earlier in order to reduce the cost on the intermediaries, make direct transaction with the manufacturers thus get the product directly and display as sale outlets. But in cases where one cannot maintain such channel has to go with the internal logistics system to get the product from the zonal or nodal warehouses. In such cases some retailers have their own vehicles to transfer the products and those who don't have will hire the logistics company and transfer the product to the customer. This work will be done perfectly by experts, named as Third Party Logistics Company. In these cases the transportation cost is always an extra cost on the customer.

Now the basic issue which arises over here is "what is the quality of work done by the out sourced company"? Contracting the work to a contractor is an easy way out, but then again, the quality of contractors and their dedication is another question which needs to be taken care.

The impact of outsourcing logistics services on supply chain can be measured as an alliance of outsourcing and logistics. As the third party logistics started getting rapid growth in the supply chain practice there is a huge expansion of technologies and services which can be implemented. In fact these types of services are the fascinating initiatives as suppliers hubs managed by the third party. Thus the proper functioning of the SCM happens when there will be an integrated and collaborative functioning of all the people connecting the retailing. 
The boom of logistics and the third party getting involved is all about the stock stored and the delivery of the goods to be done on time. To do this the retailer should have an awareness of stock available in the inventory and the process involved in storing the available stock.

\subsection{Inventory Management}

Inventory is the biggest cost factor and if not done properly will become a biggest cost drain. Thus the major benefits with SCM is reducing the inventory cost with very less stock and thus follow the JIT system, which in turn reduces the cost as well as the defective products. Thus with less stock on the brands the money can be invested on the variety of the assortments and can maintain the stock.

\subsection{Storage Facilities}

These are the facilities about the warehouses and the distribution centers or some stock rooms the retailers are having. This is where the retailer's stock the product and keep the record of the stock so as to meet the demand of the consumer. The interlink between the warehouses and the inventory maintained by the retailer will have an impact on the sales and the cost of the products.

\section{Communication and Technology}

IT is used to develop new analytical tools for operational and planning decisions that the retailers face and these types of developments will take the advantages of the capabilities offered by emerging information technologies in retailing. Consequently, a number of the decision support prototypes are getting developed and later converted into operational software systems and application software products by independent vendors. Thus IT has led to an array of retailing applications that constitute a great success story for management science and for supply chain management in particular. Hence the supply chain management will be perfect if all the suppliers work in coordination and are kept in sync with fast paced market and of course this is what the challenge. Thus today to sync or to coordinate with each other, Information Technology is giving its support in proper building of the SCM.

Technology synchronizes and balances the system at a very low cost and results in a high customer service level.

The core of SCM focuses on inventory, distribution, production, and payment cycles. As a result, the existence of information technologies, and thus, the actual information sharing among parties involved are crucial (Anantadjaya \& Nawangwulan, 2006; Li, 2002; Siem, 2005).

Harrison et al. (1999) argue that the improvements in the use of information technology will help in capturing a 'real time' data, which indicates less reliance on forecasts and create a virtual supply chain between trading partners. Therefore the improvements in the Technology are helping the partners in Supply chain to share the information and the process between partners who can later focus on their core competencies.

One of the reports says that in India a lot of technology and informational interactions are required to face the current bottlenecks of using supply chain technologies like Radio Frequency Identification, barcode scanners, Point Of Sales terminals, handheld devices and software packages. (Agarwarl, 2007)

Retailers gain Supply chain related benefits through the use of Internet like Collaborative development, timely information sharing, reduction of inventory as per the demand required, reduction in the communication cost, enhance the relationship between the customers and the retailers through customization. Easier to exploit the current markets and track the trends happening.

\section{Procurement}

Coming to the next factor is the procurement process of the product from various suppliers and stocking in the retail outlet is another important factor in the SCM practice of the retailer. Today most of the retailers look at the need and product specification for a good merchandise procurement process.

Today most of the retailers are very keen in first identifying the need and product specifications. While analyzing the price requirements, Quantity requirements, and the functional requirements are to be analyzed properly and then the brand name, time and quality while delivery are all important before the supplier is selected and then giving orders. With a proper procurement system the concept of overstocking and under stocking can be reduced and gradually concentrate on the Just in time procedure which reduce the stock and inventory.

\subsection{Demand Forecasting}

This is another factor which plays a vital role in the SCM practices. The retailers can concentrate more on the demand management and thus sell the existing products more and create demand for new products through collecting orders. 
Distribution Channel structure can be designed very meticulously and thus the flow of product between the intermediaries would decrease drastically. This will have an impact on the cost of the product and the pricing of the product before it enters the hands of the consumers.

\subsection{Reverse Logistics}

The distribution of end-of life products is another major issue which enhances the cost reduction and removing the waste products. The aspects which will be discussed in the end-of -life products flow are the design of the reverse logistics network and its interaction with the forward logistics flow, the analysis of transport routes and the internal logistics used all make important points for a better SCM practices. (Rubio, Chamorro, \& Miranda, 2006)

Vendor Managed Inventory (VMI): was first practiced in the early 1980s by Wal-Mart and Procter \& Gamble in which the vendors take up the responsibility of inventory management of retailers/customer based on sales figures made available by the retailer/customer. Nowadays, the industries outside retailing are also using the concept of VMI. VMI promises a win-win situation for both customer and manufacturer. (The IUP Journal of Supply Chain Management, Jun, 2013)

\subsection{Warehousing}

Now a day as the number of outlet for the organized retailers are increasing and in order to maintain a proper stock levels and an efficient supplies to all the outlets, most of the retailers are maintaining a centralized warehousing and from there the supplies happen to all the stores. This was the first step change in the supply of fast-moving consumer goods (FMCGs) in that buying and distribution became a headquarters function in retailing, and the logistical infrastructure created a market for third-party logistics service providers. Thus the process of Centralization enables the retailers to reduce lead time, minimize inventory and make greater product availability.

Currently the country has the most diversified and fragmented produce-supply chain. Precisely speaking about $30 \%$ of the fresh produce is always wasted before it actually reaches the market. Once the fruit is plucked from the field it has to pass six to seven intermediaries before a consumer buys it resulting in tortuous journeys, big markups and poor quality which ultimately damages the product at the end of the day.

Therefore most of the retailers in order to delight the customers are trying to replace their existing supply system with efficient network of international quality of supply chain and adapting it rightly to Indian conditions. (India Retailing, 2010)

For a retailer to assess the tradeoffs to meet the needs of the customers and parallel looking at their profits, a proper and technically evolved Supply chain process can help. Supply chain planning helps dramatically increase forecast accuracy, streamline product introductions, assess promotions and create plans attuned to the market; and supply chain execution provides transportation, warehousing and inventory management to ensure cost effective order fulfillment and on-time deliveries. (India Retailing, 2010)

If the customers don't find the goods and services promised by the retailers in the store, then obviously customers will get frustrated and they take the action which may be moving them to other retailers. Thus the customer loyalty will be lost and the retailer will lose the customers, which in turn will create loss of sales and revenues. It is known that to acquire a new customer it cost very much high rather than keeping the existing one satisfied.

The customer's order makes the starting point of the interconnected activities of supply chain and this comes to an end when the goods are delivered into the customer's hands. Waskita, 2007 quotes that to deliver goods to the end-user; it requires a network of contributions from parties involved; retailers, wholesalers, distributors, manufacturers, and raw materials suppliers.

Today the retailing is changing more and more with the increase of International retailer and brands and thus making the domestic players to be dynamic in order to survive with the competitors.

Foreign Direct Investments allows foreign retailers to operate in India. This would bring along competition and ultimately bring down the prices, thus making the economy stronger.

\subsection{Collaborative Effort}

Retail market today grow with the help of the all the stakeholders who join together and make an efficient Supply Chain by using all the latest systems of SCM as well as Logistics to take the good produce from farmers to Consumers. This collaborative system will facilitates the consumers to take the quality product at an economical price. It is evident that consumers are not only looking for the benefit they are getting from the 
product but more concerned about the value additions they are getting from the retailers and the economical prices and quality product from the retailers. All these can be achieved by an effective and efficient Supply chain Management. Thus in this process, Government and the private operators are coming together to improve lot many facilities like infrastructure, information sharing and the service required for much more better SCM practice. This is all looking at one side of the coin and the other side is the survival of the unorganized or the traditional retailing. If only the emphasis is done on the best practices followed by the organized retailers and even more trying to improve them then there will be day where all the unorganized retailers will vanish. Thus there should be some development system where the SCM practices of the traditional retailers can also be emphasized and even define them some good SCM practices so as to protect them from the organized retailers.

Thus after looking all these SCM practices in a simple way is integrating all the above and make the product reach the customer at a time which is required by him with perfect quality and above all at an affordable price. (pbr.co.in)

Summarizing the discussion above, SCM is stated as follows

The process of strategically managing the product procurement, movement, storage and the inventory (and the related information flows) through the organization and its marketing channels in such a way that current and future profitability are maximized through the cost effective fulfillment of orders. (Christopher, 1998, p. 4)

\section{Conclusion}

With the emergence of many retailers coming in the market it is necessary that specific forms of distribution or channel services are adopted. Information Technology has added value to the Supply chain management by increasing the efficiency, effectiveness and ultimately overall profitability. Parallel controlling merchandise has become very important in the retail industry. Thus with a perfect SCM the organized retailers are gaining the competitive advantage over the unorganized retailer in many aspects like inventory management, shorter time for restocking, greater efficiency and control.

As India is dominated by the unorganized retailers and about 12 million Kirana shops are prevailing. The kirana Stores are very tiny in nature and only offer a small and unreliable selection of goods. These kirana or the unorganized sector will remain the replica all over; the way they have penetrated in this country is stunted and never be scratched. As these have the advantages quick accessibility which gives the customers fast buying and by free home deliveries the organized retailers are not able to swap them on this recital.

Though the domination of the traditional sector is prevailing in the country the importance of the organized segment is increasing, the retailers should keep in mind the requirements of both the primary and secondary customers while deciding on brands and the numbers of SKU's are stocked.

Finally the traditional retailers need to look at this change and customize every issue as per the customers need. The retailer has to use an efficient logistics network, should understand and analyze the signals of market demand and plan accordingly. The product should be differentiated from the competitor's products and manage the sources of supply and develop the chain with required technology enhancement and adopt channel spanning performance measures. On the other side old and obsolete practices should be eradicated and new technologies and Supply chain practices should be implemented, so that the downstream and upstream SCM happens smoothly.

An industry with about $\$ 6.6$ trillion turnover globally and $2^{\text {nd }}$ largest employer and 18 million employments, India should do a lot on the Supply chain management to make this industry move smoothly. The collaborative effort between the parties creates basic necessities for creating the Value added services to the customers. These value added services will create the customer satisfaction and leads to a better relationship between the retailer and the customer.

In the prevailing retail industry scenario the existence and performance of the retailers will depend on the Supply Chain Management practices followed by them. A retailer can only delight a customer by his efficient supply chain practice. SCM doesn't only consist of logistics, inventory, distribution issues related with the product, but also linked with the survival of the organization. Consumers are dynamic, markets are dynamic, trends are changing, purchasing capacities and tastes are changing, and thus demand is changing and in such situation unless a retailer maintains an efficient supplier and have an integrated supply chain practice will never be successful. 


\section{References}

A study on working of modern and Traditional retail outlets: A comparative Analysis by Hemashree. (2008, July).

Aggarwal, S. (2008). Rising Mall Rentals in Major Cities Dampen Retailer's Early Euphoria. Indian Express.

Buffa, E. S. (1976). Operations Management-The Management of Productive Systems. John Wiley New York.

Chary, S. N. (n. d.). Production and Operations Management (3rd ed.). Tata McGraw Hill.

Drucker, P. F. (1981). Managing in turbulent times. Pan Books London.

Gopalkrishnan, P., \& Sunderesan, M. (1977). Materials Management-An Integrated Approach Prentice Hall. New Delhi.

Goswami, P., \& Mishra, M. S. (2009). Would Indian Consumers move from Kirana Stores to Organized Retailers when Shopping for Groceries? Asia-Pacific Journal of Marketing and Logistics. http://dx.doi.org/10.1108/ 13555850910926281

Gupta, S. L. (2007). A Study on Trends in Retailing Industry in India-A Case Study on Shopping Malls. BVIMR-Management Edge Journal of Bharati Vidyapeeth University.

Haese, D. M., \& Huylenbroeck, G. V. (2005). The rise of super markets and changing expenditure patterns of poor rural households case study in the Transkei area, South Africa. Food Policy, 30(1), 97-113. http://dx.doi.org/10.1016/j.foodpol.2005.01.001

International Journal of Production Economics (pp. 107-118, p. 62). Retail Week. (2003). At the heart of a retail giant, Retail Week, 16-18.

Kalakota, R., \& Whinston, A. B. (1996). Frontiers of Electronic Commerce Addison. Wessley.

Lee, K., \& Larry, P. R. (n. d.). Operations Management-Processes and Value Chains (7th ed.). Prentice Hall India.

Mahadevan, B. (2000). Business models for Internet based E-commerce: An anatomy' California Management Review, 42(4), 55-69. http://dx.doi.org/10.2307/41166053

Mahadevan, B. (2003). Making sense of the emerging market structures in B-2-B E-commerce. California Management Review, 46(1), 86-100. http://dx.doi.org/10.2307/41166233

Manufacturers Association for Information Technology website. (2011). About MAIT Green IT Initiatives. Retrieved from http://www.mait.com/about-mait-green-it-initiatives.php

Mridula, S. M. (n. d.). The consumption pattern of Indian Consumers: Choice between traditional and organized Retail.

Narayana, R. P. (2004). Efficiency benefits possess onto consumers: New Development.

Naylor, J. B., Naim, M. M., \& Berry, D. (1997). Legality: Integrating the lean and agile manufacturing paradigm in the total supply chain Nionth Printing $R$ Paneerselvam: Production and Operations Management Prentice Hall. India.

Norman, G., \& Greg, F. (n. d.). Operations Management (9th ed.). Thomson South Western.

Porter, M. E. (1985). Competitive Advantage-The Free Press. New York.

Proceeding of seminar on Supply chain management and problems being faced by the industry-BIMTECH-Retail market environment in India. Ind. J. Mktg., 23-25.

Ring, L. J., \& Tigert, D. J. (2001). Viewpoint: The decline and fall of Internet grocery retailers. International Journal of Retail and Distribution Management. http://dx.doi.org/10.1108/09590550110393956

Sahay B. S. (n. d.). Indian Institute of Management.

Sardana, G. D. (n. d.). Bimtech. Noida.

Sharma, V. (n. d.). Galgotia's College of Engineering \& Technology. Noida.

Slack, N., Chambers, S., Harland, S. C., Harrison, A., \& Johnson, R. (1988). Operations Management (2nd ed.). Pitman, London.

Sparks, L. (1998). In J. Fernie, \& L. Sparks (Eds.), The retail logistics transformation of Logistics and Retail Management (Chapter 1, pp. 1-22). Kogan Page, London. 
Wal-Mart Watch. (2005). Grand Opening: With a New Store Opening Nearly Every Day, What is Wal-Mart's Impact on America's Small Businesses? Wal-Mart Watch: Low Prices at What Cost? Wal-Mart Watch Annual Report, Center for Community and Corporate Ethics, 10.

William, J. S. (n. d.). Operations Management (8th ed.). Tata McGraw Hill.

Womack, J. P., Jones, D., \& Roos, D. (1990). The Machine that Changed the World: The story of lean production. Harper-Collins, New York.

Woods, C. J. U. S., Singgih, S., Adar, D., \& Drew, R. (2001). Supply chain management as beyond operational efficiency. Proceedings of the International Symposium on Tropical and Sub-tropical Fruits, Cairns, Northern Territory, Australia, 2000.

\section{Copyrights}

Copyright for this article is retained by the author(s), with first publication rights granted to the journal.

This is an open-access article distributed under the terms and conditions of the Creative Commons Attribution license (http://creativecommons.org/licenses/by/3.0/). 